\title{
RAM EXTRUSION FORCE FOR A FRICTIONAL PLASTIC MATERIAL: MODEL PREDICTION AND APPLICATION TO CEMENT PASTE
}

Paper presented at the Annual European Rheology Conference, Grenoble, April 2005

\author{
ARNAUD PERROT \\ LGCGM équipe matériaux, INSA de Rennes \\ 20, avenue des buttes de Coesmes 35043 Rennes, France \\ arnaud.perrot@ens.insa-rennes.fr \\ CHRISTOPHE LANOS \\ LGCGM équipe matériaux, IUT de Rennes \\ 3, rue du Clos Courtel - BP 9042235704 Rennes CEDEX 7 \\ christophe.lanos@univ-rennes1.fr \\ PATRICE ESTELLÉ
}

LGCGM équipe matériaux, INSA de Rennes

20, avenue des buttes de Coesmes 35043 Rennes, France

patrice.estelle@insa-rennes.fr

YANNICK MELINGE

LGCGM équipe matériaux, INSA de Rennes

20, avenue des buttes de Coesmes 35043 Rennes, France

yannick.melinge@insa-rennes.fr

\begin{abstract}
We developed a model to predict the ram extrusion force of frictional plastic materials such as cement based pastes. The extrusion of cement based material has already been studied but interaction between shaping force and paste behaviour still has to be understood. Our model is based on the plastic frictional behaviour of cement based materials and integrates the physical mechanisms that govern material extrusion flow and extrusion force increase. When the process starts, a pressure gradient is created in the extruder due to wall friction of the paste which is submitted to plug flow. It induces a consolidation of the material. As a result, a large increase of extrusion force appears. A Coulomb law is used to model cement based materials which is considered as consolidating granular media. Such modelling is compared with experimental results. Tests were carried out on extrudible cement pastes. Modelling and experimental results are in good agreement.
\end{abstract}

Key words: frictional plastic material, cement based material, extrusion, filtration, ram extruder 


\section{Introduction}

The aim of this study is firstly to characterize the extruder flow behaviour of frictional plastic materials -such as cement based materials- and to study the physical mechanisms that govern the forming process. Secondly, the paper establishes a method of predicting the extrusion force of such materials. This modelling enables to predict the coupled behaviour of different extruder/paste combinations.

In ram-extrusion process, plastic materials flow as a plug and slip with friction along the extruder wall (Obermayer, 1965; Tresca, 1872; Zienckiewitz, 1974; Zienckiewitz, 1977; Jay and Magnin, 2002). Extrusion of cement based material has already been studied in previous works but none of them mentioned the time dependent ram extrusion behaviour of such paste materials (Mori and Baba, 1994; Stang and Pedersen, 1996; Srinivasan et al., 1999; Mu et al., 1999; Qian et al., 2003).

In the present work, the rheological and tribological behaviour of the extrudible cement based material is linked to the ram extrusion geometry in order to predict the flow evolution during the process. Extrudible cement based materials behave as a high yield stress and heterogeneous materials (liquid phase and granular skeleton). The effects of the extrusion process (long time, high pressure gradient, low velocities) may affect the local composition of the material and change the flow conditions. Such a paste presents a behaviour which depends on the stress path induced by the extrusion process. Our extrudible cement paste behaves as a consolidating plastic soil with time dependent flow properties. Such variations of paste homogeneity inside the extruder are included in the present modelling. During the process, friction creates high pressure gradient that induces liquid or cement paste filtration through the granular skeleton.

Liquid filtration during the extrusion of high solid volume fraction pastes is a well known process that has already been observed by Burbidge et al. (1995), Götz et al. (2001) and Götz et al. (2002). Recently, the extrusion ability of cement pastes has been studied (Toutou et al., 2004; Toutou et al., 2005) using a simple squeeze flow. The authors have shown that cement based materials with a high solid volume fraction behaves as a frictional plastic material. This induces a high sensitiveness to fluid filtration during slow flow and high pressure gradient. During extrusion flow, cement paste can be modelled as a consolidated soil where the interparticular friction is dominant. Modelling commonly used in soils mechanics (Coulomb or Drücker-Prager models) describes such behaviour. The first one is presently used for our frictional plastic material. In ram extrusion, the material is confined and the internal pressure increases as the process goes on. As a result, friction forces between particles increase and induce a higher macroscopic yield stress. The rheological and tribological modelling parameters depend also on the paste location. Finally, during the process, yield stress and wall friction stress always increase because the paste is always submitted to consolidation. Extrusion force increases and may lead to a blockage of the extrusion process.

Along the extruder wall, in the plug flow zone, the granular paste slips with friction. In order to model the tribological behaviour, the wall shear stress is linked to the normal stress. Then, the wall shear stress is related to the axial stress acting on the material in the direction of the ram movement. This relationship is similar to the Janssen based on the Janssen theory used by Ovarlez (2004) to study 
the behaviour of confined sands. In the Janssen theory, the pressure acting on the granular media is linearly linked to the axial and normal stresses.

\section{Figure 1}

In the case of axisymetrical extruder with square entry die, we assume that extrusion force can be decomposed in two different force components: the shaping force required to deform the plastic material through the die and the friction force due to friction of the material during the plug flow occurring in the pipe zone (Fig. 1).

The shaping force of a plastic body has already been modelled by Benbow et al. (1993), Mortreuil et al. (2000) or Hill (1950). These authors showed that there is a relationship between the ratio of extrusion (the ratio of the exiting diameter $d$ to the entering diameter D) and the force needed to deform the material. These works only deal with perfect plastic or viscoplastic materials. During the extrusion process of purely plastic materials, the required force that ensures extrusion is constant. This constant force is not reached in the extrusion of frictional plastic materials as the paste is evolving inside the extruder during the process.

In order to apply the developed model, we performed ram extrusion tests on a cement paste. Two extruder bodies initially filled with different quantities of paste were used. The extrusion ratio is kept constant $(\mathrm{d} / \mathrm{D}=0.35)$. Ram displacement and extrusion force were recorded during time and the paste homogeneity is particularly observed during the process to evaluate water filtration effects. Experimental results are compared with the proposed model.

\section{Description of the ram-extrusion process}

The properties of extrusion flow are well known for plastic and visco-plastic materials. Numerical simulations see for example Zinckiewitz (1977), show that axisymetrical extrusion flow is divided into three parts (Fig. 2).

- A plug flow, in the central area where the paste slips along the wall. Near the extruder wall, a highly shearing flow zone can be located in a very thin layer. - Near the die, a sheared flow zone, where the material is forming. This zone is called the "shaping zone".

\section{Figure 2}

- A zone where the material remains stationary around the die entry. This area is called the "dead zone".

\section{Figure 3}

The numerical works of Horrobin and Nedderman (1998) or Jay and Magnin (2002) have confirmed this kind of flow behaviour for viscoplastic materials with a high yield stress. Experimental results on kaolin paste extrusion were presented by Toutou (2002) and confirmed the numerical results (Fig. 3).

We decompose the extrusion force in both different forces acting in different zones as shown on figure 4 :

- The shaping force described by Hill (1950), Benbow (1993) or Mortreuil (1998) which is required to give his final shape to the material. We assume that the shaping force $\mathrm{F}_{\mathrm{pl}}$ varies as the material flows. This variation is due to the material consolidation which depends on the pressure history of the material flowing through the pipe of the extruder. Then, $\mathrm{F}_{\mathrm{pl}}$ is proportional to the plastic yield value $\mathrm{K}$. 
- The friction force $F_{\text {fr, }}$ which is required to allow the material to slip at the wall of the pipe extruder. The friction force also increases because of the material consolidation. $\mathrm{F}_{\mathrm{fr}}$ is linked to the friction yield value $\mathrm{K}_{\mathrm{w}}$.

\section{Figure 4}

As described on figure $4, \mathrm{~L}_{\mathrm{dz}}$ denotes the dead zone length and $\mathrm{L}$ is the friction length. $\sigma(\mathrm{L})$ represents the mean axial stress. $\sigma(0)$ is the mean axial stress at the shaping zone entry. Reference pressure is the external pressure $\mathrm{P}_{\mathrm{atm}}=0$.

\section{Cement pastes: an extrudible frictional plastic material}

\section{Concept of extrudability}

The concept of extrudability is described by Toutou et al. (2004) as shown on figure 5. The authors describe for a ram extruder an extrudability domain, defined by appropriated geometrical parameters and material behaviour parameters. In this work, results are expressed using extrusion stress and forming ration d/D.

\section{Figure 5}

A good quality of extrudates requires a balance between the process and the rheological properties of the material. The material must be soft enough to flow into the pipe and through the extrusion die, and sufficiently firm to retain the shape given by the die geometry without skin defects. The extrusion ability of a cement based paste relies on the pastes behaviour. The paste cohesion provides the final shape of the material. Also, plastic and friction yield stresses are directly linked to the energy required to deform the material through the die and may affect the surface quality of the final product. The relationship between extrusion force and both rheological and tribological properties is crucial for the choice of an extruder that ensures the extrusion flow.

\section{Rheological behaviour of extrudible frictional plastic behaviour}

Mansoutre (1998) and Toutou and co-workers (2002, 2004, 2005) showed that extrudible cement based material exhibits both frictional and plastic behaviours. Consequently, such materials are very sensitive to fluid filtration with a redistribution of the interstitial fluid pressure. Such occurring process is enhanced by the stress gradient which appears during extrusion flow. Squeeze tests carried out by Toutou et al. $(2002,2004,2005)$ showed that cement pastes behaviour depends on shear rate. At high shear rate, cement pastes exhibits purely plastic behaviour whereas at low shear rate (which corresponds to extrusion), water filtration produces and induces paste hardening. This hardening induced a yield stress increase which is typical of a frictional plastic behaviour. In order to model the rheological behaviour of cement pastes material we use the Coulomb model in order to describe the sensitive behaviour to pressure (see eq. 1).

$$
\mathrm{K}=\mathrm{K}_{0}+\text { b. } \mathrm{P}_{\max }
$$

Where $\mathrm{K}$ is the plastic yield stress, $\mathrm{K}_{0}$ is the cohesion (plastic yield stress at reference pressure), $\mathrm{b}$ is a friction parameter and $\mathrm{P}_{\max }$ denotes the maximal value of pressure known by the media. This model is validated performing simple 
Casagrande box tests on a cement paste (cement, water and a water reducing admixture) defined in section 5.1. Shear velocity is $1 \mathrm{~mm} / \mathrm{min}$ and the evolution of the apparent yield stress according to the applied normal stress as plotted on figure 6 . Results show a linear relationship between yield stress and applied normal stress. The linearity is characteristic of a Coulomb material.

\section{Figure 6}

We also have to take into account the fact that pastes keep the yield stress value obtained when the pressure acting on the granular media is the highest known by the material (under $\mathrm{P}_{\max }$ ). In such conditions, the material consolidates and the pressure effect is irreversible. This memory effect which characterizes consolidated soils study is very important in this model and makes the material dependent on the stress path (similarly to consolidating soils).

The initial pressure gradient, created at the beginning of the extrusion, induces variations of the material properties such as yield stress or wall stress that become dependent on the paste location. The paste located in the plug flow zone and reaching the shaping zone presents evolving rheological properties. In our extrusion tests, carried out at very high pressure gradient, we consider that filtration time is negligible compared with extrusion process time. This is the reason why that consolidation is assumed to be an instantaneous phenomenon. In case of mortars or concrete, there can be different scales of filtration as the material presents different scales of heterogeneity (liquid phase through cement grains, or cement paste through sand grains...). We here assume that all filtration processes reach to the paste consolidation. As a result, all the filtration processes are integrated in our modelling like a global process that induces paste hardening. In order to simplify the flow modelling, compressibility is neglected. Therefore, a compressibility of the granular skeleton is suspected but not integrated to the modelling.

\section{Tribological behaviour of cement pastes}

The tribological behaviour is modelled by a Coulomb law. We assume that wall stress depends on the normal stress acting on the material. Moreover, when the paste consolidates, the friction yield stress increases. We model the wall stress by a Coulombian law defined by equation (2).

$$
\mathrm{K}_{\mathrm{w}}=\mathrm{K}_{\mathrm{w} 0}+\mathrm{a} \cdot \mathrm{N}_{\max }
$$

Where $\mathrm{K}_{\mathrm{w}}$ is the friction yield stress, $\mathrm{K}_{\mathrm{w} 0}$ is the friction yield stress at reference pressure and $\alpha$ is a friction parameter. $\mathrm{N}_{\max }$ is the maximal value of the normal stress acting on the wall surface.

\section{Paste behaviour in the axisymetrical extrusion flow}

In order to link the model parameters which describe the material behaviour in the axisymetrical extrusion flow to the axial stress $\sigma$, the Janssen theory is used. It gives a simple way to model the stress distribution in a granular media in the axisymetrical cylinder. According to Janssen theory, the pressure $\mathrm{P}$ acting on the granular media is proportional to the mean axial stress $\sigma$. The normal stress acting on the extruder wall surface $\mathrm{N}$ is also proportional to $\sigma$. The Janssen stress distribution allows us to write the following relationships suitable in a granular media confined in an axisymetrical extruder pipe.

$$
\mathrm{K}_{0}=\mathrm{K}+\beta \cdot \sigma_{\max }
$$




$$
\mathrm{K}_{\mathrm{w}}=\mathrm{K}_{\mathrm{w} 0}+\alpha \cdot \sigma_{\max }
$$

Where $\alpha$ and $\beta$ are frictional local parameters and $\sigma_{\max }$ is the maximum value of the axial pressure acting on the studied material.

\section{Theorical Analysis of the extrusion flow of frictional plastic material}

\section{Stress profile in the extruder}

When the ram moves, friction stress occurs at the paste/extruder boundary interface. The friction force creates a pressure gradient in the paste that induces liquid filtration. Liquid pressure equilibrium and consolidation in the paste affect the local rheological and tribological properties of the extruded paste. It is assumed that paste consolidation is instantaneous. So actualized yield stress and wall stress are directly linked to the axial stress inside the extruder (eq. (1) and (2)). At a given position $\mathrm{z}$ (Fig. 4), the mean axial stress $\sigma(\mathrm{z})$ is assumed to be constant. From the force balance equation on an elementary cylindrical layer, the following relationship is obtained:

$$
\frac{\pi \mathrm{D}^{2}}{4}[-\sigma(\mathrm{z}+\mathrm{dz})+\sigma(\mathrm{z})]+\pi \mathrm{D} \tau_{\mathrm{w}}(\mathrm{z}) \mathrm{dz}=0
$$

Where $\tau_{\mathrm{w}}(\mathrm{z})$ is the wall friction stress at the position $\mathrm{z}$. The previous equation becomes:

$$
\frac{\mathrm{d} \sigma(\mathrm{z})}{\mathrm{dz}}=\frac{4 \tau_{\mathrm{w}}(\mathrm{z})}{\mathrm{D}}
$$

Combining equation (4) and (6), we finally obtain the following equation depending on the axial stress $\sigma(\mathrm{z})$.

$$
\frac{\mathrm{d} \sigma(\mathrm{z})}{\mathrm{dz}}-\frac{4 \alpha}{\mathrm{D}} \sigma(\mathrm{z})-\frac{4 \mathrm{~K}_{\mathrm{w} 0}}{\mathrm{D}}=0
$$

Equation (5) is solved in order to find the axial stress profile which is created when the material is submitted to the axial stress at the starting of the process.

$$
\sigma(\mathrm{z})=\frac{\mathrm{K}_{\mathrm{w} 0}}{\alpha}\left[\exp \left(\frac{4 \alpha \mathrm{z}}{\mathrm{D}}\right)-1\right]+\sigma(0)
$$

Where $\sigma(0)$ is the vertical stress needed to ensure the plastic shaping of the material through the die. In order to evaluate this shaping stress, the Hill's equation is used and links linearly the extrusion force to the paste yield stress. It represents the plastic energy required to ensure the flow of the material in a channel of diameter $\mathrm{d}$.

$$
\sigma(0)=K_{0}(\pi+2)\left(1-\frac{d}{D}\right)=\gamma K_{0}
$$

When the extrusion flow is initiated, the local axial stress increases. The local stress $\sigma(z)$ is the maximum stress known by the material. As a result, the material consolidates. As the process goes on, this stress value increases and the material consolidates. Consequently, the value $\sigma(\mathrm{z})$ calculated in equation (8) is equal to 
the value $\sigma_{\max }(\mathrm{z})$, the highest value of axial stress which has been applied to the granular media.

The determination of the initial stress profile is totally determined allows computing the initial force that initiates the material shaping. the stress profile in the extruder induces a relationship between the flow properties of the paste and its location in the extruder. As a consequence, the yield stress $\mathrm{K}$ and the wall friction stress $\mathrm{K}_{\mathrm{w}}$ depend on $\mathrm{z}$ (Fig. 7).

\section{Figure 7}

This first modelling step gives us the force needed to initiate the flow. This force is influenced by the quantity of paste in the extruder. $\mathrm{L}_{0}$ denotes the length of paste moving along the extruder wall (zone concerned by the plug flow). The length of the dead zone $\mathrm{L}_{\mathrm{dz}}$ (Fig. 4), has to be withdrawn to the original total paste length in order to calculate $\mathrm{L}_{0}$.

For a given ram advance, the paste arriving in the shaping zone presents a higher yield stress related to the paste formed the moment before. In fact, the consolidation process continues. Therefore, the axial stress $\sigma(\mathrm{z})$ becomes a function of the ram position, the axial stress $\sigma$ is now noted $\sigma(\mathrm{z}, \mathrm{L})$ where $\mathrm{L}$ is the ram position.

\section{Shaping force evolution}

The shaping force increases when more consolidated material flows into the shaping zone. We calculate the evolution of rheological properties according to the ram advance. As a result, the evolution of $\mathrm{K}$ according to the ram position $\mathrm{L}$ is written as the L-derivate of $\mathrm{K}$ (The $\mathrm{K}$ profile follows the ram displacement).

$$
\frac{\partial \mathrm{K}(0, \mathrm{~L})}{\partial \mathrm{L}}=\frac{4 \beta \mathrm{K}_{\mathrm{w} 0}}{\mathrm{D}} \cdot \exp \left(\frac{4 \alpha}{\mathrm{D}} \mathrm{L}\right)
$$

Then, the evolution of the shaping stress vs. the ram position is easily deduced.

$$
\frac{\partial \sigma(0, \mathrm{~L})}{\partial \mathrm{L}}=\frac{4 \beta \gamma \mathrm{K}_{\mathrm{w} 0}}{\mathrm{D}} \cdot \exp \left(\frac{4 \alpha}{\mathrm{D}} \mathrm{L}\right)
$$

In order to calculate the plastic shaping force $\mathrm{P}(0, \mathrm{~L})$ at a given ram position $\mathrm{L}$, we integrate the shaping force variation between the initial ram position $\mathrm{L}_{0}$ and the calculated position L.

$$
\sigma(0, \mathrm{~L})=\gamma\left[\mathrm{K}_{0}+\frac{\beta \mathrm{K}_{\mathrm{w} 0}}{\alpha}\left(\exp \left(\frac{4 \alpha}{\mathrm{D}}\left(\mathrm{L}_{0}-\mathrm{L}\right)\right)-1\right)\right]
$$

The increase of the shaping force increases the axial stress values. Afterwards, the effect of the evolution of the shaping force are included for the computation of the axial stress acting on the ram $\sigma(\mathrm{L}, \mathrm{L})$.

\section{Friction force evolution}

The axial stress value increases exponentially with ram advance due to the evolution of the shaping force, as seen on equation 12. Then, this increase of $\sigma(\mathrm{z}, \mathrm{L})$ according to $\mathrm{L}$ affects the value of friction force. A derivation of equation (8) according to L writes: 


$$
\frac{\partial \sigma(\mathrm{z}, \mathrm{L})}{\partial \mathrm{L}}=\frac{4 \beta \gamma \mathrm{K}_{\mathrm{w} 0}}{\mathrm{D}} \cdot \exp \left(\frac{4 \alpha}{\mathrm{D}} \mathrm{L}\right)
$$

From equation (4) and (13), the L-derivate of $K_{w}(z, L)$ is obtained.

$$
\frac{\partial \mathrm{K}_{\mathrm{w}}(\mathrm{z}, \mathrm{L})}{\partial \mathrm{L}}=\frac{4 \alpha \beta \mathrm{K}_{\mathrm{w}}}{\mathrm{D}} \cdot \exp \left(\frac{4 \alpha}{\mathrm{D}} \mathrm{L}\right)
$$

From the evolution of the friction stress $\mathrm{K}_{\mathrm{w}}$ according to the ram position, the total vertical stress acting on the ram is calculated by combining the integrated friction force with the shaping force given by equation (10).

$$
\sigma(\mathrm{L}, \mathrm{L})=\gamma\left[\mathrm{K}_{0}+\frac{\beta \mathrm{K}_{\mathrm{w}}}{\alpha}\left[\exp \left(\frac{4 \alpha}{\mathrm{D}} \mathrm{L}_{0}\right)\left(\exp \left(\frac{4 \alpha}{\mathrm{D}}\left(\mathrm{L}_{0}-\mathrm{L}\right)\right)-1\right)\right]\right]
$$

The stress acting on the ram is now determined for every ram positions, integrating friction and consolidation effects due to physical characteristics of frictional plastic media.

\section{Experimental results}

\section{Material}

The chosen material fills all the extrudability criterion defined by Toutou et al. (2004,2005). The material must be rigid enough to retain its shape under gravity and handy solicitations. We carried out tests with a cement pastes with a water/cement weight ratio of 0.22 . A water reducing admixture (sika plastiment $22 \mathrm{~S}$ ) is added to the water in the following proportion: $\mathrm{P} / \mathrm{C}=0.01$. The binder used is a mix of 70 percent of Portland cement 32.5 CEM IIB with 20 percent of volcanic rock (pozzolane) finely crushed ( $15 \mu \mathrm{m}$ maximum particle diameter), 5 percent of silica fume $(0.1 \mu \mathrm{m}$ maximum particle diameter $)$ and 5 percent of amorphous crushed quartz $(10 \mu \mathrm{m}$ maximum particle diameter). The addition of filler fines gives better homogenisation and plastic performance to the final paste.

\section{Procedure}

A planetary Hobart mixer is used for mix. It provides sufficient high shear rates for small batches. Dry ingredients are first mixed during two minutes at the lowest rpm setting. Then, water and plasticizer are added. Once the dry ingredients are moistened, a higher rotation speed is applied during 5 minutes. Tests are performed 30 minutes after the mixing in order to avoid aging and setting effects. Vane tests are performed in order to control plastic properties of the cement pastes. Then, the required quantity of paste is put in the extruder and precompressed at $100 \mathrm{~N}$ to ensure same initial conditions between each test. The highest ram speed is used in order to limit filtration effects in this precompression phase. Then, die is put on the extruder instead of the plug and the test is performed. Two steel extruders pipes of diameters $D_{1}=43.3 \mathrm{~mm}$ and $D_{2}=$ $55.3 \mathrm{~mm}$ are used; the extrusion ratio d/D remains constant and equals to 0.35 . The wall surface of steel pipes is smooth. For each extruder, three different quantities of pastes were tested (initial length $\mathrm{L}_{\mathrm{ini}}=\mathrm{L}_{0}+\mathrm{L}_{\mathrm{dz}}$ ), in order to observe the influence of paste quantity on extrusion force. Extrusion force and ram displacement were recorded versus time using a data acquisition system. 


\section{Results and discussions}

\section{Table 1}

For the six tests configurations, it is assumed that the material in the same conditions and aging state. The plastic yield stress of the cement pastes $\mathrm{K}_{0}$ is measured using a vane test and is equal to $20 \mathrm{kPa}$ (result obtained as the maximum shear stress value at low rotational rate). The internal friction parameter $\beta$ is measured with a squeeze test method given by Toutou $(2004,2005)$ and is equal to 0.53 . This result is confirmed by Casagrande box tests, as previously described. Friction stress $\mathrm{K}_{\mathrm{w} 0}$ is measured with a translation tribometer and its value is $15 \mathrm{kPa}$. At this step, the parameters $\alpha$ and $\mathrm{L}_{0}$ are not identified or measured. They are finally determined from the best match estimation between modelled and experimental curves. The model parameters for the six tests are given in table 1 .

\section{Figure 8a-b}

Experimental and modelled effort vs. remaining material length curves are confronted in figure 8a-b. In all cases, the modelled curves (obtained with same $\alpha, \beta, \gamma, \mathrm{K}_{0}, \mathrm{~K}_{\mathrm{w}}$ and with close values of $\mathrm{L}_{0}$ ) and, as expected, match quiteperfectly the experimental ones.

\section{Figure 9a-d}

However, for two tests (noted D55,3 L71 and D43 L41) there is slight variation between experimental and modelled curves. This variation is due to the material state of aging. Slight variation in the material aging and composition can explain the curve difference. Moreover, there can be small error in the evaluation of the friction length.

In order to verify these arguments, the model is computed with for different values of the material behaviour parameters. The variations of extrusion forces according to slight variation of modelling parameters (Fig. 9a-d) are sufficiently large to explain the difference between experimental and modelled curves. The experimental error is located in the area of reproducibility defined by the material sensibility at aging, mixing and composition procedure. We only plot the error caused by a variation on $\mathrm{K}_{\mathrm{w}}, \mathrm{L}_{0}$ and $\alpha$ because they are the more relevant parameters of the present modelling.

Figure 9a-d shows the influence of the material modelling parameters on the computed extrusion force. It is obvious that plastic yield stress and internal friction parameter $\beta$ do not subsequently influence the extrusion force. Therefore, the material shaping is not responsible for the extrusion force increase. In contrast, we can say that a slight deviation in the wall friction stress and in the wall friction parameter $\alpha$ greatly affects the extrusion force. The material wall friction stress $\mathrm{K}_{\mathrm{w}}$ and the sensibility of wall friction to the axial stress (model by the $\alpha$ parameter) are the key parameters that govern the extrusion force increase. Equation (15) shows that the extrusion force increases linearly with $\alpha$ and exponentionaly with $\mathrm{K}_{\mathrm{w}}$. Indeed, friction is the source of the material consolidation. Moreover, an increase of $\alpha$ affects the gradient pressure which enhances the paste consolidation. Due to the material consolidation, wall friction stress value also increases. This double mechanism explains how influent the parameter $\alpha$ is in our modelling.

\section{Table 2}


The physical phenomenon which is responsible of the extrusion force increase and extrusion blockage is the friction along the extruder wall. Friction induces paste consolidation that makes the paste harder to extrude. At the beginning of the process, the force required to overcome wall friction is ten times the force required to form the material through the die (Table 2). The model can be written as follow, using exponential law and splitting effects of friction from plasticity effects. The friction (YOpl and Apl) and plastic components (YOfr and Afr) can be calculated:

$$
\mathrm{F}=\mathrm{Y} 0 \mathrm{pl}+\mathrm{Y} 0 \mathrm{fr}+(\mathrm{Apl}+\mathrm{Afr}) \cdot \exp (-\mathrm{L} / \mathrm{t} 0)
$$

Table 2 shows that the component of extrusion force due to friction effects is dominant over the component due to plastic forming. This table confirms that friction is the parameter that governs extrusion force and extrusion blockage.

\section{Friction lengths determination}

The friction surface modelled by the parameter $\mathrm{L}_{0}$, as mentioned in section 4.1 , have to be estimated according to experimental observations. Agreement has to be found between experimental results and modelling fit. To evaluate this parameter similarly to slip lines theory, flow geometry is assumed for the forming process, as shown on figure 10 .

\section{Figure 10 Figure 11}

No physical phenomena depending on the cement paste intrinsic behaviour have been found in order to explain the variation of $\mathrm{L}_{0}$ with change of initial paste quantity.

Tests and model fit shows that the initial friction zone length tends to a critical value of $42 \mathrm{~mm}$ with an increase of initial paste quantity (Fig. 11). A study of paste consolidation and cement paste skeleton permeability has to be performed. This study may validate the hypothesis of a dead zone length limited by a critical relative velocity between liquid and the granular skeleton. In this case, our assumption of instantaneous material consolidation is a practical approximation, but for more accuracy, a hydro-mechanic coupling must be studied. Without this coupling, no relationship linking $\mathrm{L}_{0}$ with $\mathrm{L}_{\mathrm{ini}}$ and the modelling parameters of the granular media behaviour appears.

\section{CONCLUSIONS}

The proposed model gives a simple way to predict the extrusion force of a frictional plastic material. The modelling is suitable to characterize the extrusion conditions of an extrudible firm cement paste. The modelling enables to understand the mechanism of increasing extrusion force and extrusion blockage. Friction at the extruder wall creates a pressure gradient that induces hardening and consolidation of the paste. As the process goes on, the material arriving in the die land becomes firmer and the friction force increases as the material becomes more and more consolidated. As a result, the extrusion force increases exponentionaly. The crucial role of wall friction force as a dominant part of the total extrusion force is highlighted. The model was confronted with tests on a firm cement pastes. Rheological modelling parameters are measured and are included in the model. The length of the friction zone is evaluated and tends to a critical value with the 
increase of paste quantity. Additional tests and investigations have to be performed in order to link the friction length value to microstructure and physics of the cement pastes. A hydro-mechanical coupling may be envisaged in order to complete the study of paste consolidation during extrusion process. This work has to be extended to optimize the extrusion process of such materials with a minimisation of the friction force. Tests with lubricated walls or flow coupling with vibration have to be performed in order to reduce wall friction effects. 


\section{REFERENCES}

Benbow JJ, Bridgwater J (1993) Paste Flow and extrusion, Clarendon Press, Oxford, 1993

Burbidge AS, Bridgwater J, Saracevic Z (1995) Liquid migration in Paste Extrusion, Trans. IchemE, Vol 73, Part A, pp 810-816

Götz J, Kreibich W, Peciar M (2002) Extrusion with a piston extruder for the determination of the local solid and fluid concentration, the local porosity and saturation and displacements profiles by means of NMR imaging, Rheol. Acta, Vol 41, pp 134-143

Götz J, Zick K, Kreibich W (2003) Possible optimisation of pastes and the according apparatus in process engineering by MRI flow experiments, Chemical engineering and processing, Vol 42, pp 517-534

Hill R (1950) Mathematical theory of plasticity, Clarendon Press, Oxford

Horrobin DJ, Nedderman RM (1998) Computational analysis of the extrusion of soft solid, $1^{\text {st }}$ Esaform Congress, Sophia Antipolis, pp 461-464

Jay P, Magnin A, Piau JM (2002) Numeriacal simulation of viscoplastic fluid flows trough an axisymmetric contraction, Transaction of the ASME, Vol 124, pp 700-705

Mansoutre S, Colombet P, Van Damme H (1999) Cement and Concrete Research, Vol 29, pp 1441-1453 Mori A, Baba A (1994) A method for predicting the operating characteristics during extrusion moulding process for cementitious materials, Proc. Int. Symp., Brittle Matrix Composites 4', Warsaw

Mortreuil FX, Lanos C, Laquerbe M (2000) A model for recombining clay paste plastic flow in dies, XIIIth International congress on Rheology, vol. 3, British society of Rheology, Cambridge, pp 400-402

Von Obermayer A (1865) Versuche über des Ausflussplastichen Tons., S. B. Akad. Wiss., Wien, Vol 58, pp 737

Mu B, Li Z, Chui SNC, Peng J (1999) Cementitious composite manufactured by extrusion technique, Cement and concrete research, Vol 29, pp 237-240

Ovarlez G, Fond C, Clément E (2002) Overshoot effect in the Janssen granular column : a crucial test for granular mechanics, Phys. Rev. Lett, E67

Qian X, Zhou X, Mu B, Li Z (2003) Fiber alignment and property direction dependency of FRC extrudates, Cement and Concrete Research, Vol 33, pp 1575-1581

Srinivasan R, DeFord D, Shah S P (1999) The use of extrusion rheometry in the development of extruded fiber-reinforced cement composites, Cement Sc and Eng, 1, pp 26-36

Stang H, Pedersen H (1996) HPFRCC - Extruded pipes, Matrials for the new millennium, Edited by Ken P. Chong, Vol 2, pp 261-270

Toutou Z (2002) Rhéologie des suspensions concentrées : évaluation des conditions d'extrudabilté, Ph-D thesis, INSA de Rennes

Toutou Z, Lanos C, Mélinge Y (2004) The use of squeezing test-extrusion flow similitude to identify cement based materials extrudability, Proc. XIVth Int. Congr. On Rheology, Seoul, Korea, MP23

Toutou Z, Roussel N, Lanos C (2005) The squeezing test, a tool to identify firm cement based material's rheological behaviour and evaluate their extrusion ability, Cement and Concrete Research, accepted Tresca H (1872) Application de l'écoulement des corps solides au laminage et au forgeage, Mèm. Sav. Acad. Sci. Inst. France, Sc. Math. et Phys., Vol. XX, pp 138

Zienkiewicz OC, GodbolePN (1974) Flow of plastic and viscoplastic solids with a special reference to extrusion and forming process, Int. J. Num. Meth. In Engng., Vol 8, pp 3-16

Zienkiewicz OC, Jain PC, Onate E (1977) Flow of solids during forming and extrusion : Some aspects of numerical solutions, Int. J. Solid Structures, Vol 14, pp 15-38 


\section{Figure caption}

Fig. 1: modelled force acting on the axisymetrical cylinder of extruded material.

Fig. 2: extrusion flow properties obtained by numerical simulations of the extrusion flow of a plastic material (Zienkiewicz, 1977).

Fig. 3: flow properties of a purely plastic material: application to a kaolin paste (Toutou, 2002).

Experimental extrusion performed with coloured layers superposition.

Fig. 4:flow model, and stress localisation in the example of extrusion flow of frictional plastic material.

Fig. 5: extrudability domain defined in Toutou $(2002,2004,2005)$

Fig. 6: results of Casagrande box tests on the studied cement paste (shear velocity: $1 \mathrm{~mm} / \mathrm{s}$ ). Study of the material sensitivity to normal stress $\sigma_{\mathrm{n}}$. Linear evolution of the yield stress according to normal stress.

Fig. 7: evolution of the local material properties due to local paste consolidation due to the increase of the extruder axial stress.

Fig. 8: $\mathrm{F}=\mathrm{f}(\mathrm{L})$ effort vs. remaining material length curves : experimental vs. modelled for three initial length and two extruder diameters: $8 \mathrm{a} \mathrm{D}=43,3 \mathrm{~mm}$ and $8 \mathrm{~b} \mathrm{D}=55,3 \mathrm{~mm}, \mathrm{~d} / \mathrm{D}=0.35$

Fig. 9: model sensitivity to modelling parameters (9a: $\left.K_{w}, 9 b: \alpha, 9 c: K_{0}, 9 d: \beta\right) . L_{\text {initial }}=58 \mathrm{~mm}$ and $\mathrm{D}=43,3 \mathrm{~mm}$

Fig. 10: visualisation of the influence of paste quantity on the dead zone length

Fig. 11: evolution of the initial friction length according to the initial total length of material in the extruder for the studied cement paste 


\section{Table caption}

Table 1: parameters used in the test modelling. $\mathrm{D}$ gives the extruder diameter and $\mathrm{L}$ is the initial material lenght inside the extruder

Table 2: friction and plastic proportion in the total extrusion force 


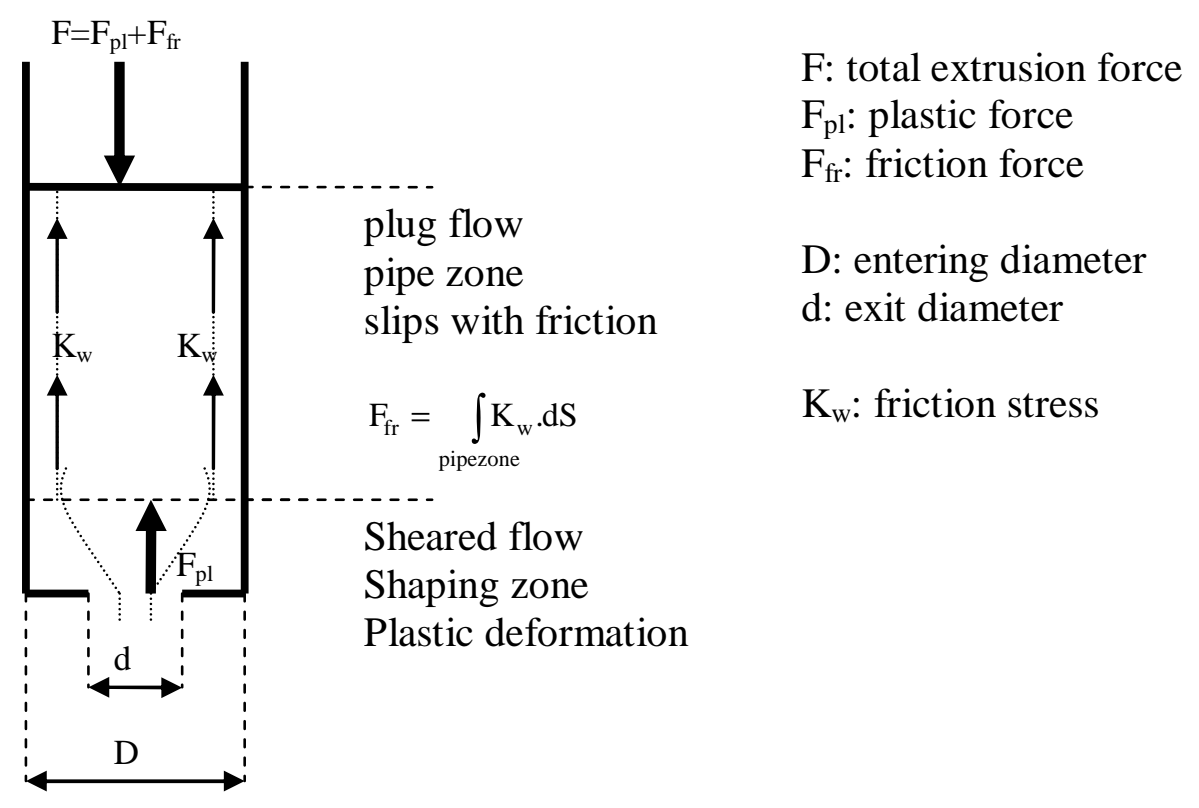

Fig. 1 


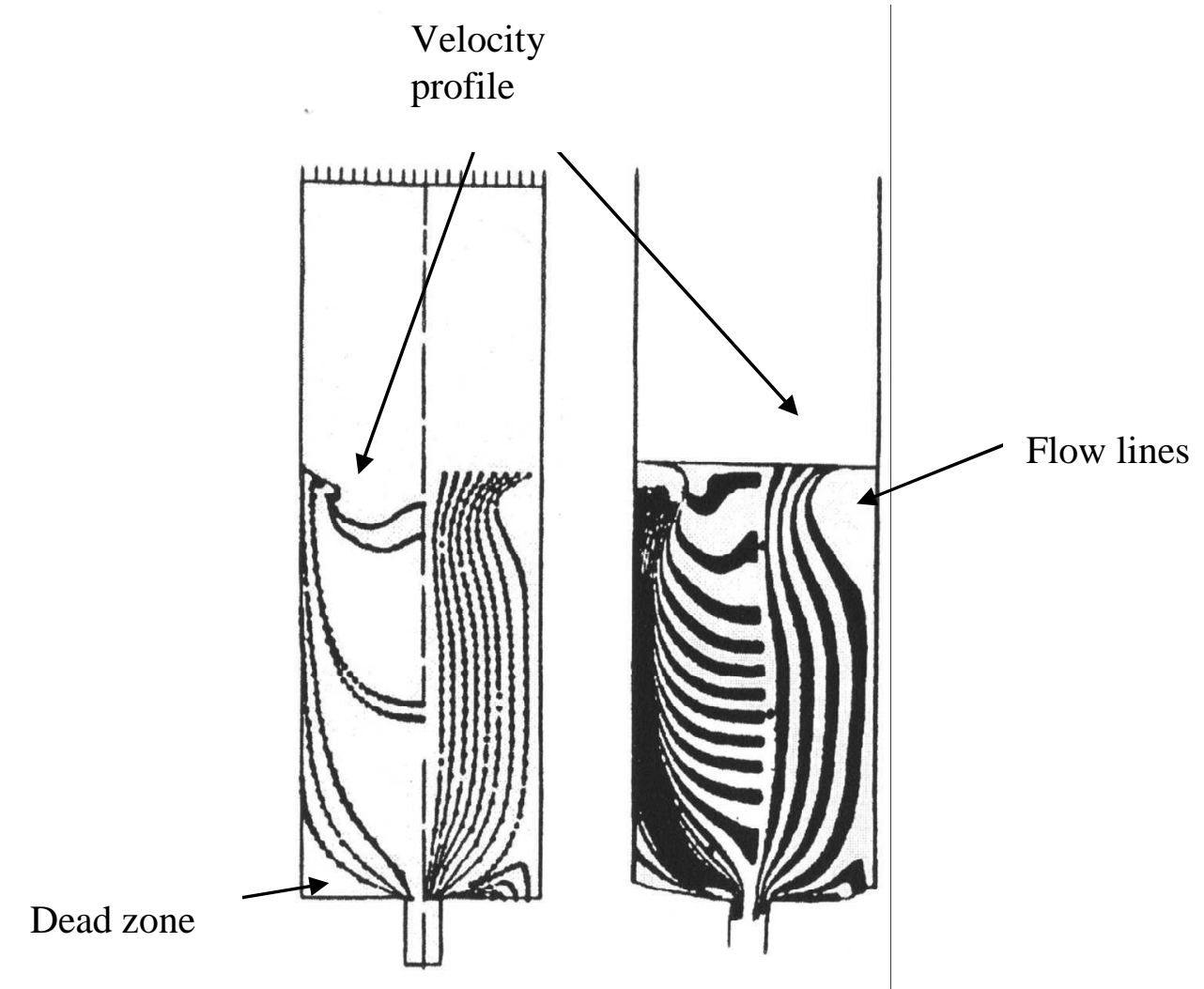

Fig. 2 


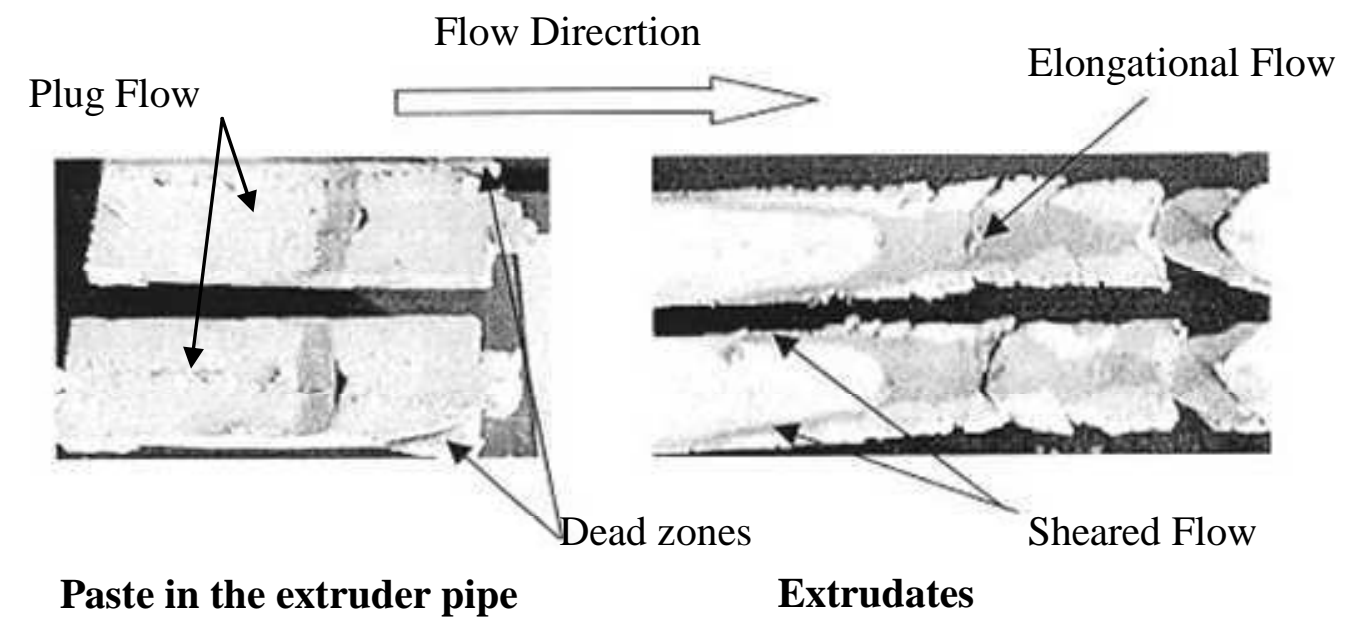

Fig. 3 


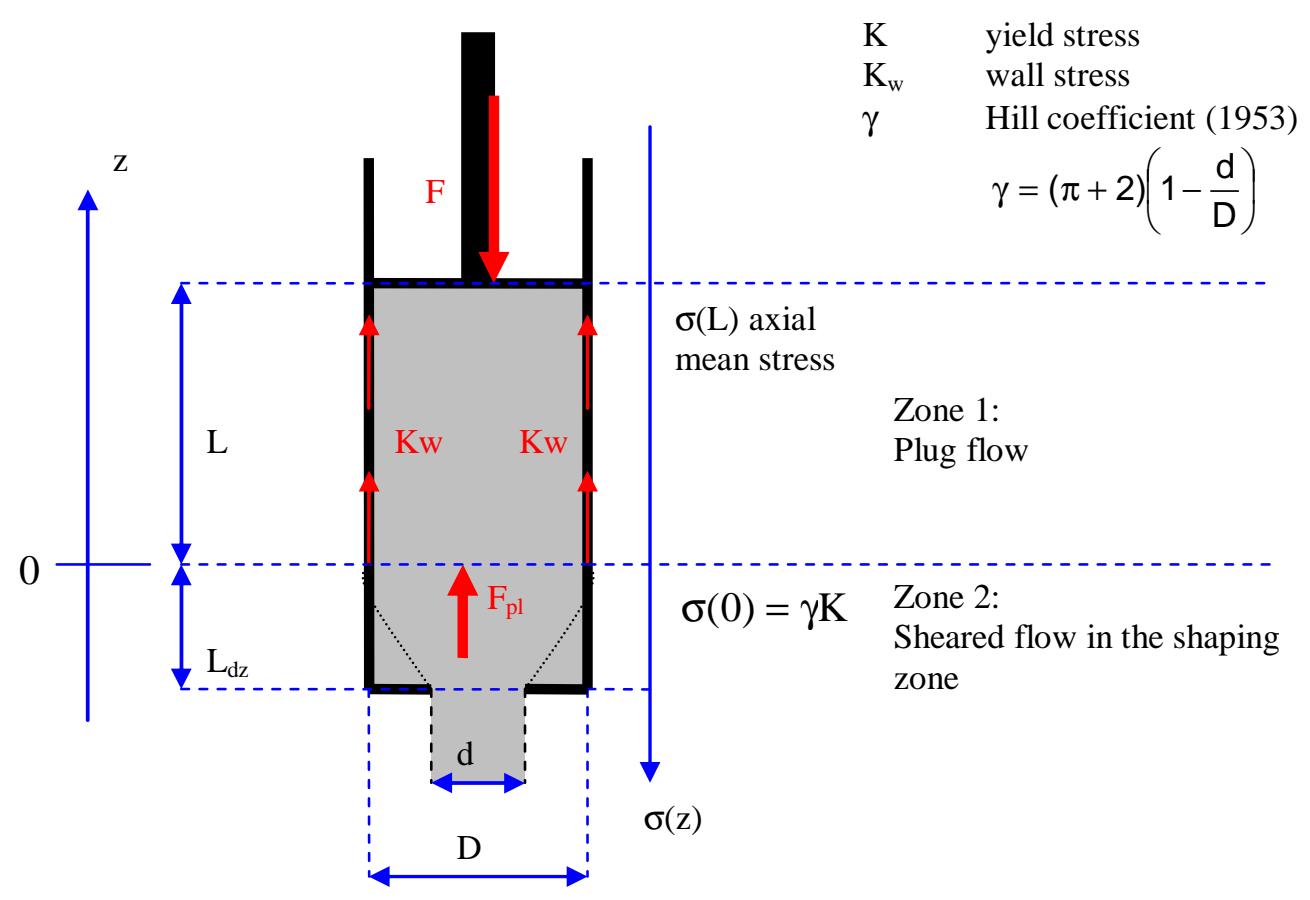

Fig. 4 


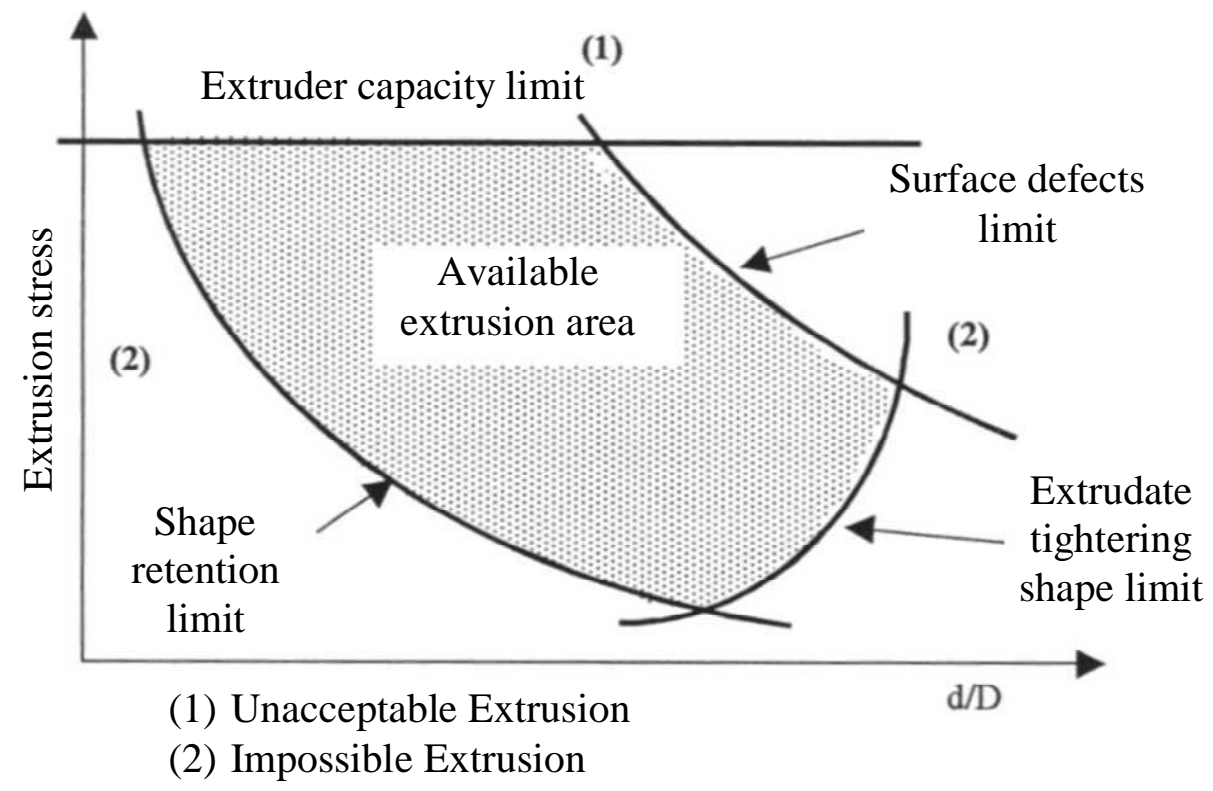

Fig. 5 


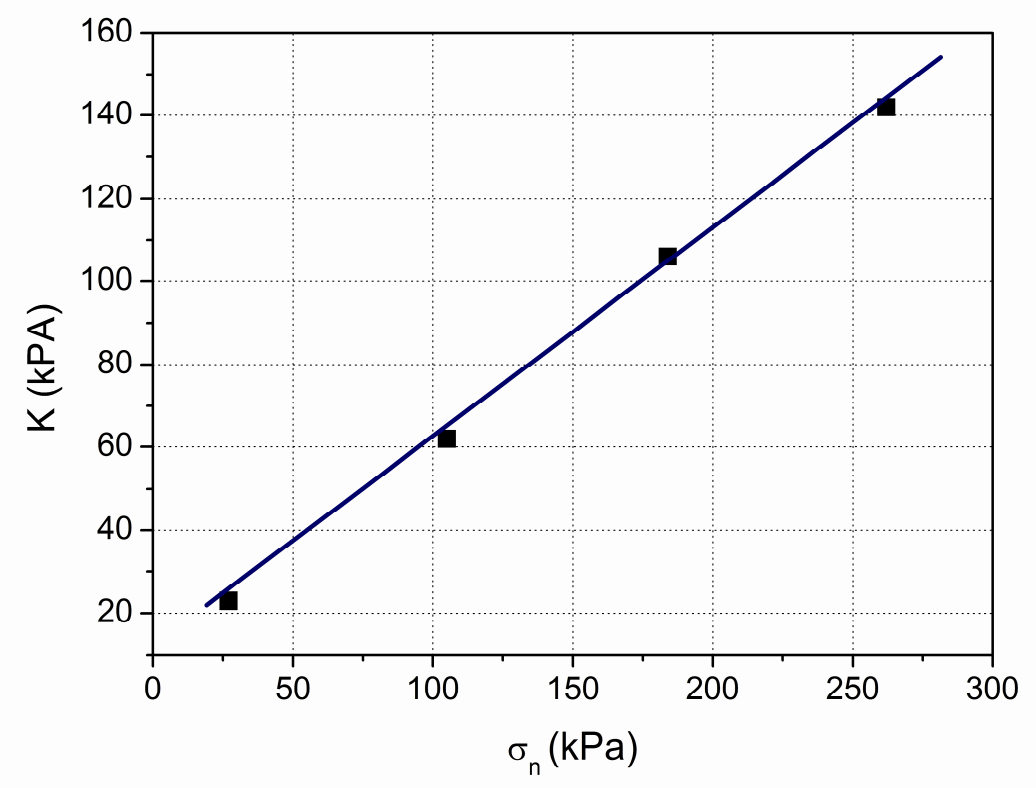

Fig. 6 


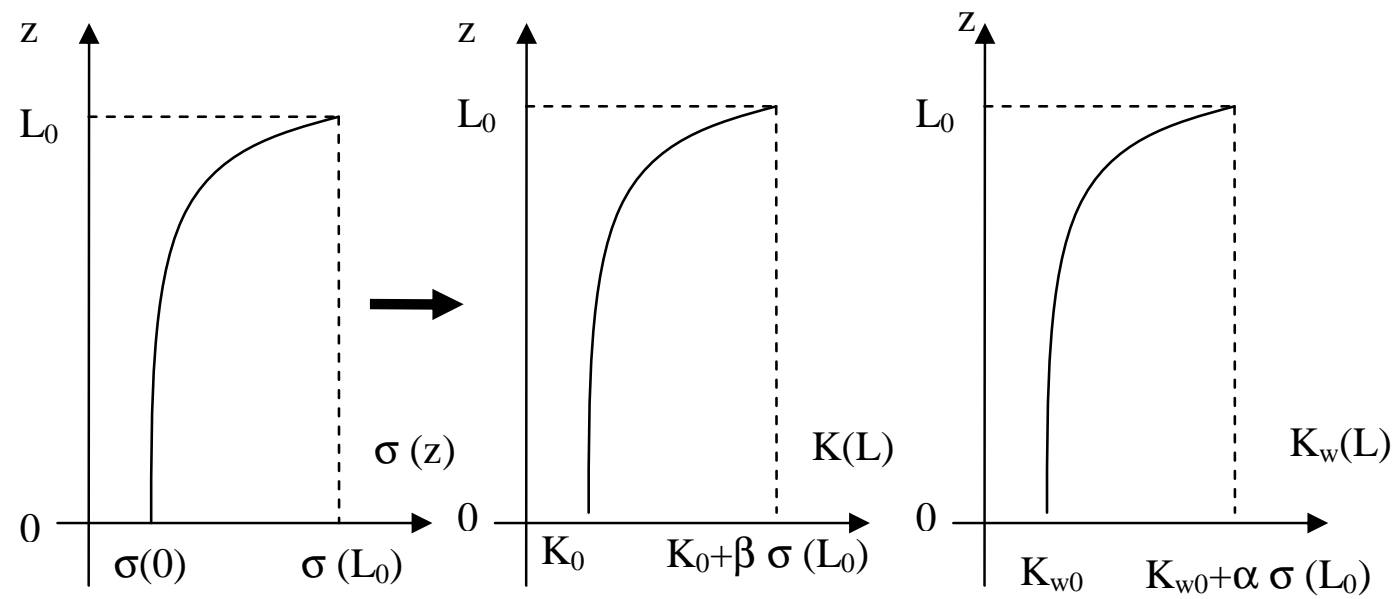

Fig. 7 


\begin{tabular}{ll|cccccc} 
& & $\mathrm{D} 43,3$ & $\mathrm{D} 43,3$ & $\mathrm{D} 43,3$ & $\mathrm{D} 55,3$ & $\mathrm{D} 55,3$ & $\mathrm{D} 55,3$ \\
& & $\mathrm{~L}_{\text {ini }} 58$ & $\mathrm{~L}_{\text {ini }} 80$ & $\mathrm{~L}_{\text {ini }} 41,5$ & Lini86 & Lini71 & Lini107 \\
\hline$\alpha$ & & 1 & 1 & 1 & 1 & 1 & 1 \\
$\beta$ & & 0,53 & 0,53 & 0,53 & 0,53 & 0,53 & 0,53 \\
$\gamma$ & & 5,14 & 5,14 & 5,14 & 5,14 & 5,14 & 5,14 \\
$\mathrm{~K}_{0}$ & $\mathrm{~Pa}$ & 20000 & 20000 & 20000 & 20000 & 20000 & 20000 \\
$\mathrm{~K}_{\mathrm{w}}$ & $\mathrm{Pa}$ & 15000 & 15000 & 15000 & 15000 & 15000 & 15000 \\
$\mathrm{D}$ & $\mathrm{mm}$ & 43,3 & 43,3 & 43,3 & 55,3 & 55,3 & 55,3 \\
$\mathrm{~L}_{\text {ini }}$ & $\mathrm{mm}$ & 58 & 80 & 41,5 & 86 & 71 & 107 \\
$\mathrm{~L}_{0}$ & $\mathrm{~mm}$ & 39,44 & 42 & 37,14 & 43,86 & 44,02 & 43,87
\end{tabular}

Table 1 


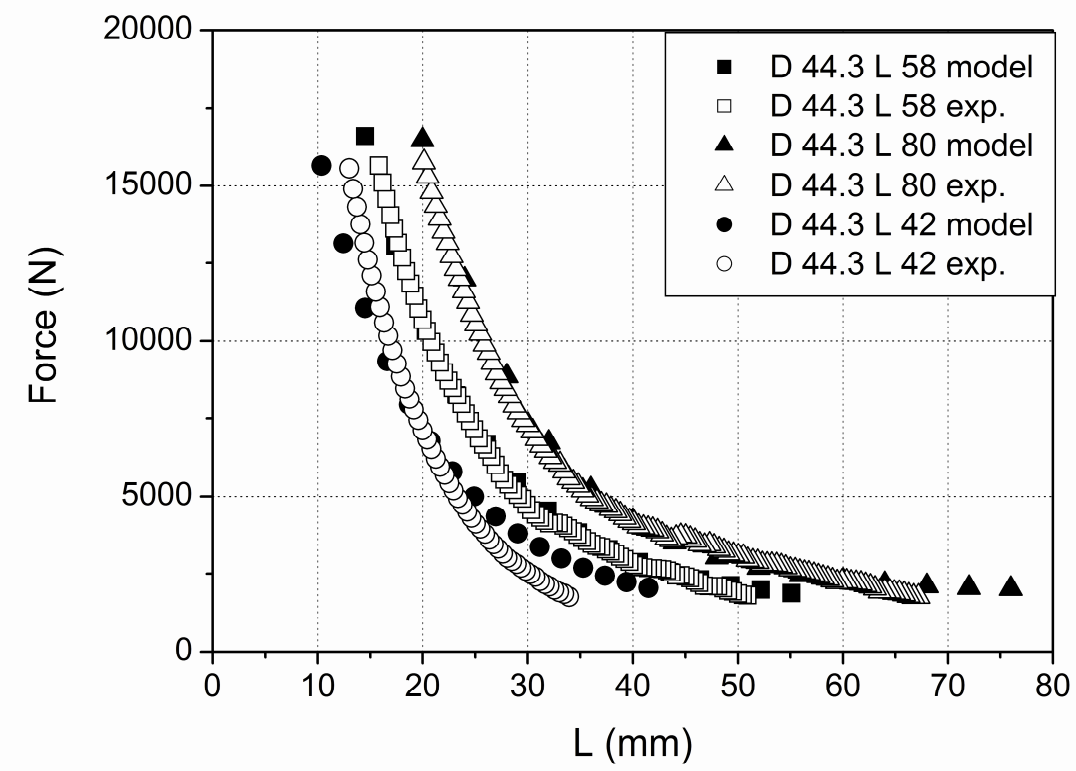

Fig 8a

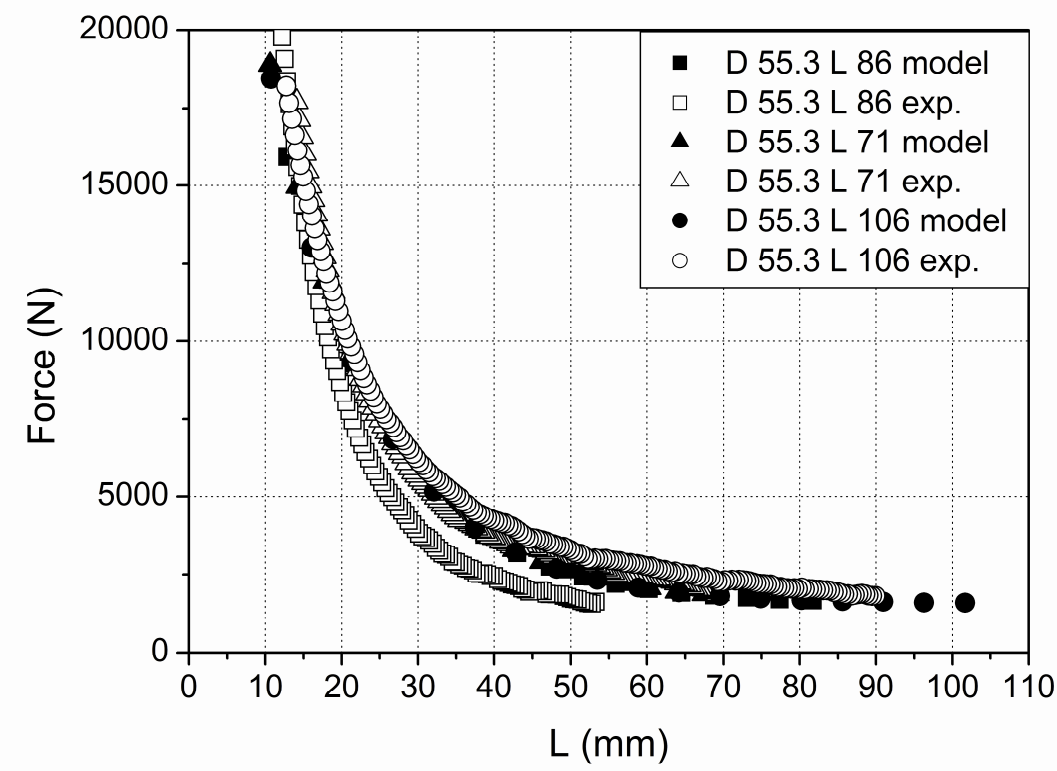

Fig. 8b 


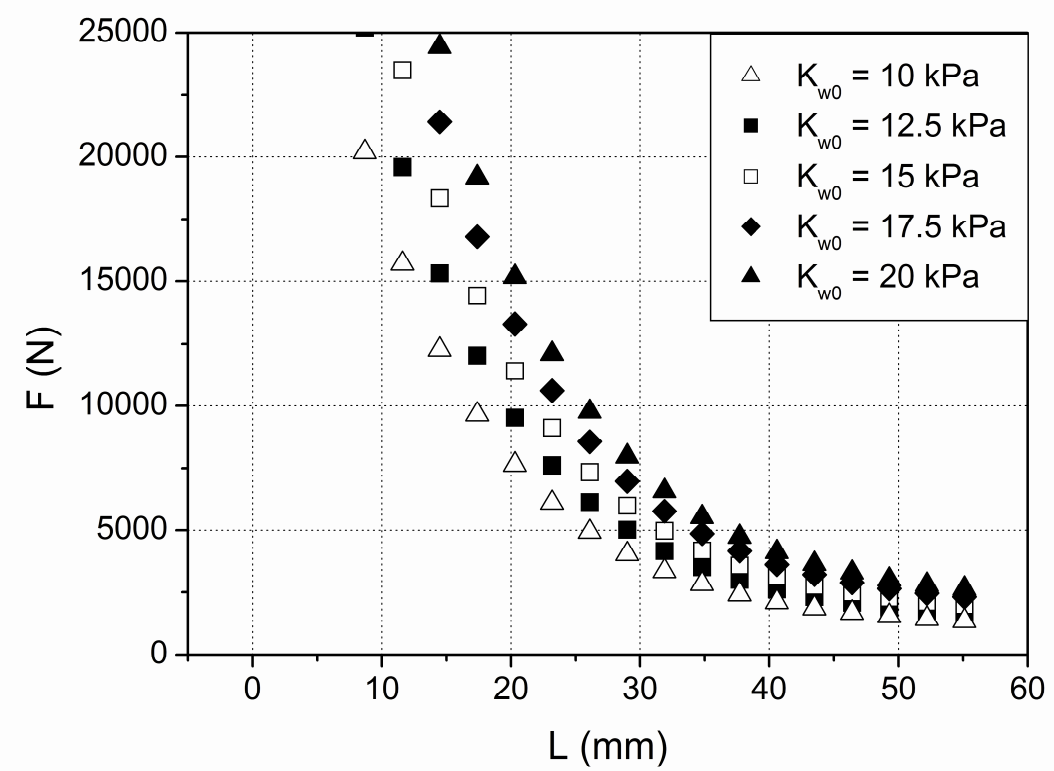

Fig. 9a

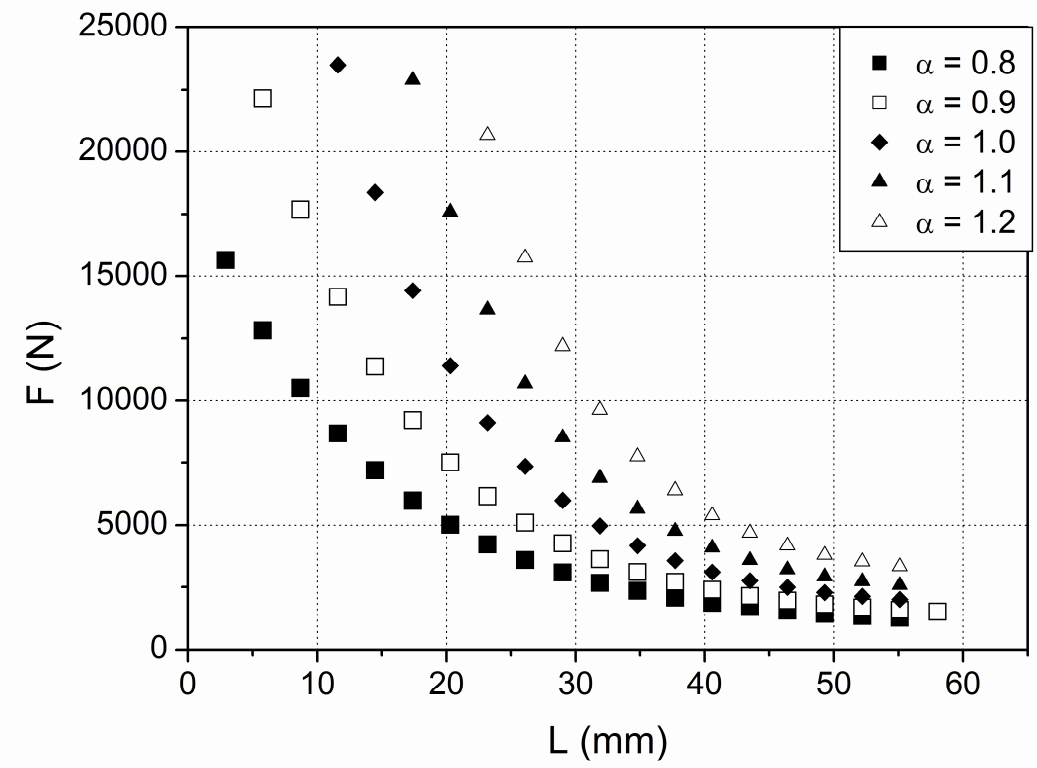

Fig. 9b 


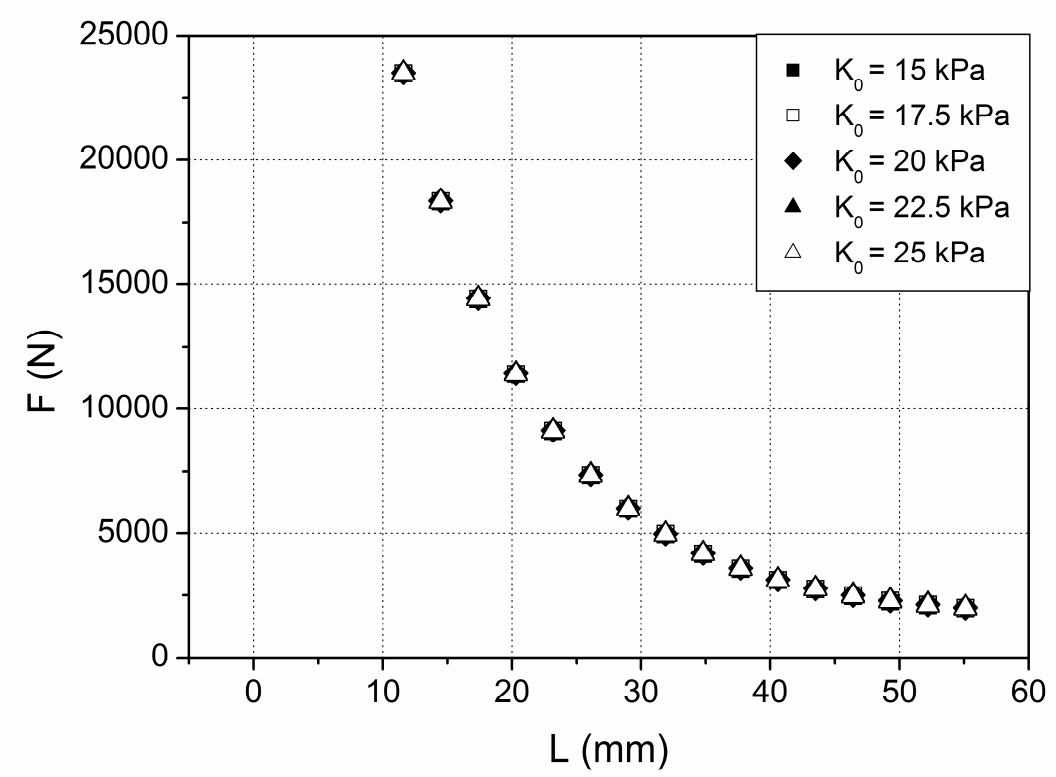

Fig. 9c

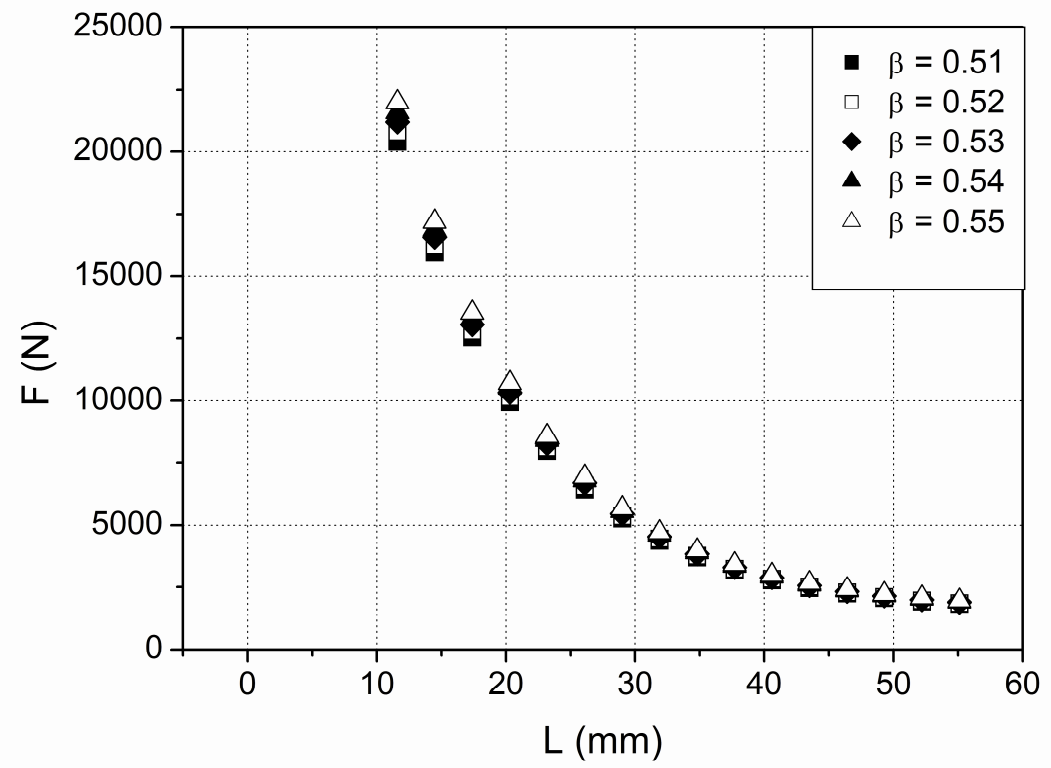

Fig. 9d 


\begin{tabular}{c|cccccc} 
& $\mathrm{D} 43,3 \mathrm{~L}_{\text {ini }} 58$ & $\mathrm{D} 43,3 \mathrm{~L}_{\text {ini }} 80$ & $\mathrm{D} 43,3 \mathrm{~L}_{\text {ini }} 41,5$ & $\mathrm{D} 55,3 \mathrm{~L}_{\text {ini }} 86$ & $\mathrm{D} 55,3 \mathrm{~L}_{\text {ini }} 71$ & $\mathrm{D} 55,3 \mathrm{~L}_{\text {ini }} 107$ \\
\hline $\mathrm{Y} 0_{\mathrm{pl}}(\mathrm{N})$ & 60 & 60 & 60 & 97 & 97 & 97 \\
$\mathrm{Y} 0_{\mathrm{fr}}(\mathrm{N})$ & 1464 & 1864 & 1176 & 1466 & 1483 & 1467 \\
$\mathrm{Y} 0(\mathrm{~N})$ & 1523 & 1924 & 1236 & 1563 & 1581 & 1564 \\
& & & & & & 1531 \\
$\mathrm{~A}_{\mathrm{pl}}(\mathrm{N})$ & 1503 & 1904 & 1215 & 1530 & 1548 & 35032 \\
$\mathrm{~A}_{\mathrm{fr}}(\mathrm{N})$ & 55940 & 90278 & 36358 & 34980 & 35817 & 36563 \\
$\mathrm{~A}(\mathrm{~N})$ & 57443 & 92182 & 37574 & 36510 & 37365 & \\
$\mathrm{t} 0(\mathrm{~m}-1)$ & 0,0924 & 0,0924 & 0,0924 & 0,0723 & 0,0723 & 0,0723 \\
$1 / \mathrm{t} 0(\mathrm{~m})$ & 10,825 & 10,825 & 10,825 & 13,825 & 13,825 & 13,825
\end{tabular}

Table 2 


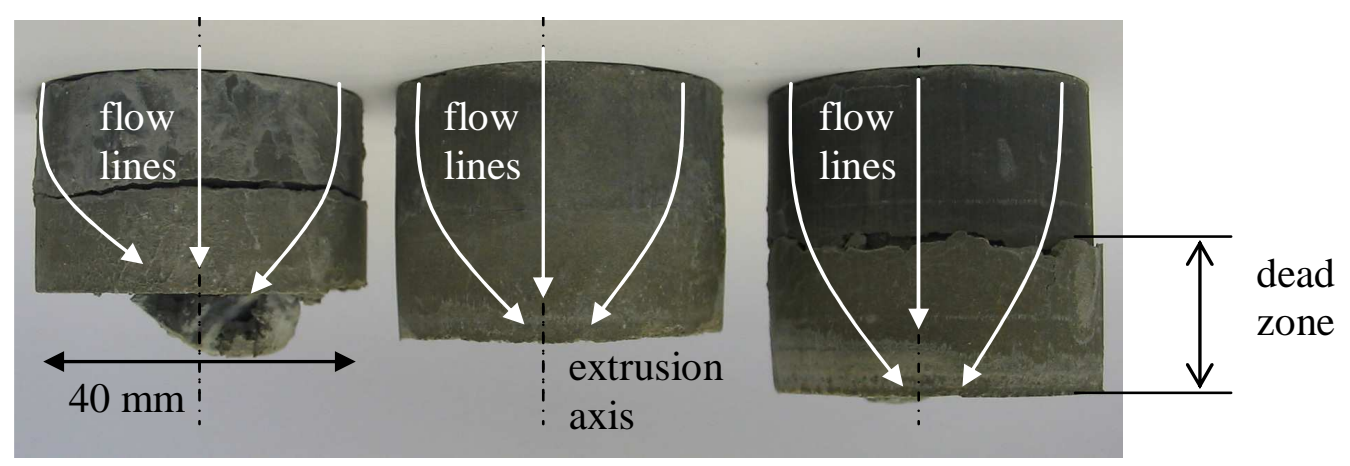

Fig. 10 


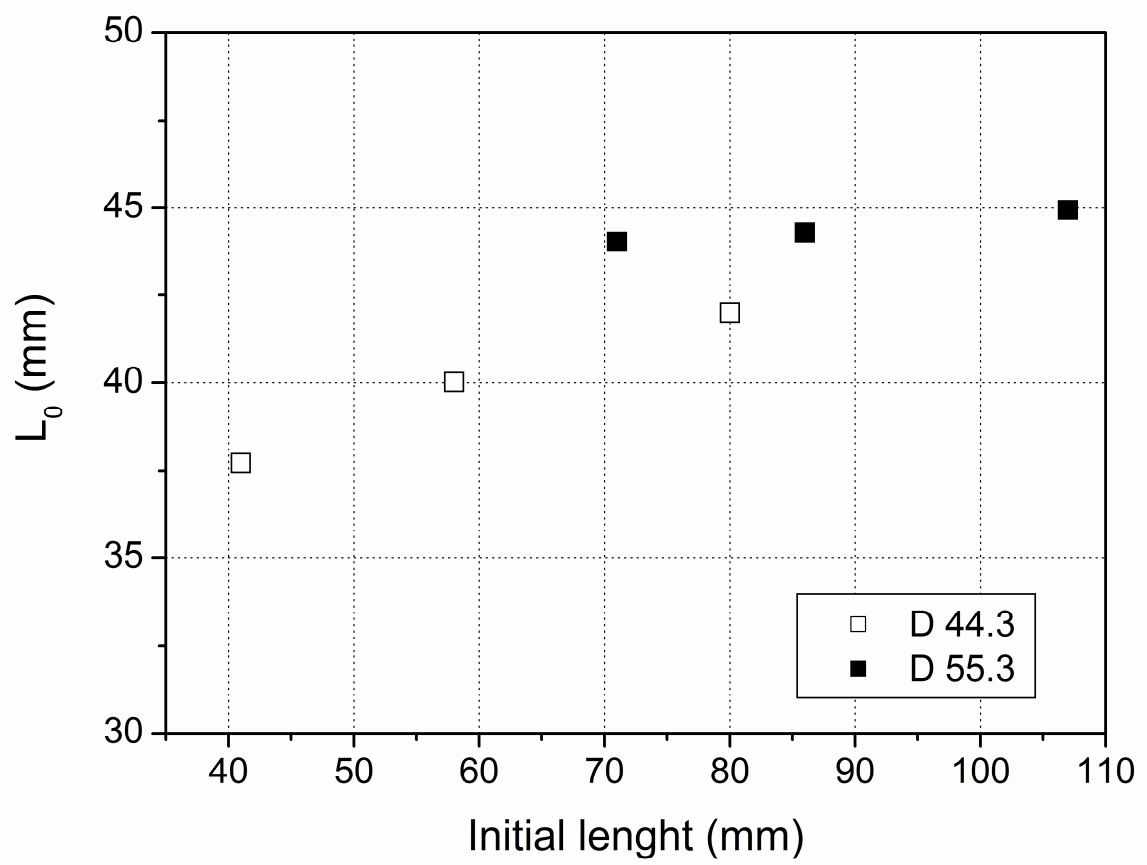

Fig. 11 